\title{
A Forty-Six-Year-Old Man With Tracheomegaly and Bronchiectasis
}

\author{
Abbas Fadaii ${ }^{1,{ }^{*},}$, Bahador Bagheri ${ }^{2}$ \\ ${ }^{1}$ Department of Internal Medicine, Faculty of Medicine, Shahid Beheshti University of Medical Sciences, Tehran, IR Iran \\ 2 Department of Pharmacology, Faculty of Medicine, Semnan University of Medical Sciences, Semnan, IR Iran \\ *Corresponding author: Abbas Fadaii, Department of Internal Medicine, Faculty of Medicine, Shahid Beheshti University of Medical Sciences, Tehran, IR Iran. Tel.:+98-2122580333, Fax: \\ +98-2122580335, E-mail: abbasfadaii@gmail.com.
}

Received: April 06, 2012; Revised: April 20, 2012; Accepted: May 01, 2012

Tracheomegaly or tracheobronchomegaly is a rare syndrome which is characterized by dramatic dilatation of the trachea and the major bronchi. This syndorme is usually associated with chronic respiratory infection and airway obstruction. In this paper, a case with tracheomegaly and bronchiectasis was scrutinized.

Keywords: Bronchomegaly; Tracheomegaly; Mucociliary Clearance

\section{Introduction}

Mounier-Kuhn Syndrome is a rare and genetic disorder which is described by dilatation of the trachea and the main bronchus $(1,2)$. The patients suffering from this disease mainly complain about chronic coughs, purulent sputum and recurrent infection of the lower respiratory tract (3). It was not until 1932 that MounierKuhn Syndrome was first described. It usually initiates primarily with no specific cause hitherto. Autopsy findings suggest a congenital defect or atrophy of elastic tissues or smooth muscles of the trachea and main bronchus (3-5). Moreover, tracheobronchomegaly is also described in association with Ehlers-Danlos syndrome, Marfan syndrome, Kenny-Caffey syndrome, and Brachmann-de Lange syndrome $(6,7)$. However, the disease typically discloses sporadically. There exists a male predominance, additionally patients are usually adults (1). The symptoms of tracheomegaly are sputum production due to bronchiectasis and infection of the lower respiratory tract. The blockade in mucociliary clearance and inefficient cough mechanism are likely to result in recurrent pneumonia, bronchiectasis, and fibrosis in airways which are markedly dilated. Patients may develop dyspnea and respiratory failure due to extensive damage to the lungs. Furthermore, pneumothorax, hemoptysis and finger clubbing may develop $(4,8)$. The diagnosis of syndrome is based on chest roentgenogram or CT scan. In females, the transverse diameter of trachea exceeding $21 \mathrm{~mm}$ and the diameter of the right and left main bronchus exceeding $19.8 \mathrm{~mm}$ and $17.4 \mathrm{~mm}$ is suggestive for Mounier-Kuhn syndrome. In males, the cut-off is $25 \mathrm{~mm}$ for trachea, $21.1 \mathrm{~mm}$ and $18.4 \mathrm{~mm}$ for right and left main bronchus, respectively $(9,10)$.

\section{Case Presentation}

A forty-six-year-old man was referred to Sasan Hospital, Tehran, Iran to evaluate a chronic cough which has been going on for 20 years. He complained about mucoid sputum which was sometimes purulent and bloody. He is a farmer who does not smoke. He denied fever, dyspnea, or weight loss. He had no history of admission, allergy or systemic diseases. There was also no history of respiratory diseases, TB or similar symptoms in his family. Physical examinations proved that the patient was conscious and well-nourished without respiratory distress. The vital signs were normal whereas respiratory rate was 25/ min. Respiratory examination revealed crackles at both lungs which was changed by coughing. Finger clubbing was not found. Chest X-ray (Figure 1) and Chest CT scans (Figure 2 and 3 ) were performed. The results showed tracheomegaly with dramatic increase in the diameters of the trachea and a modest increase in the diameters of the right and left-main bronchi.

Mild bronchiectasis was also present in right lung. Body plathysmogrophy disclosed a slight decrease in pulmonary volumes with a restrictive pattern. A bronchoscopy was performed and revealed complete atrophy of the trachea membranes. No diverticular outpunching was found. Sputum and tracheal samples were negative for TB.

Implication for health policy/practice/research/medical education:

The case under study presents a patient with tracheomegaly, characterized by chronic cough, dyspnea and poor quality of life.

Copyright ( ) 2012, Shahid Beheshti University of Medical Sciencces;. This is an Open Access article distributed under the terms of the Creative Commons Attribution License (http://creativecommons.org/licenses/by/3.0), which permits unrestricted use, distribution, and reproduction in any medium, provided the original work is properly cited. 


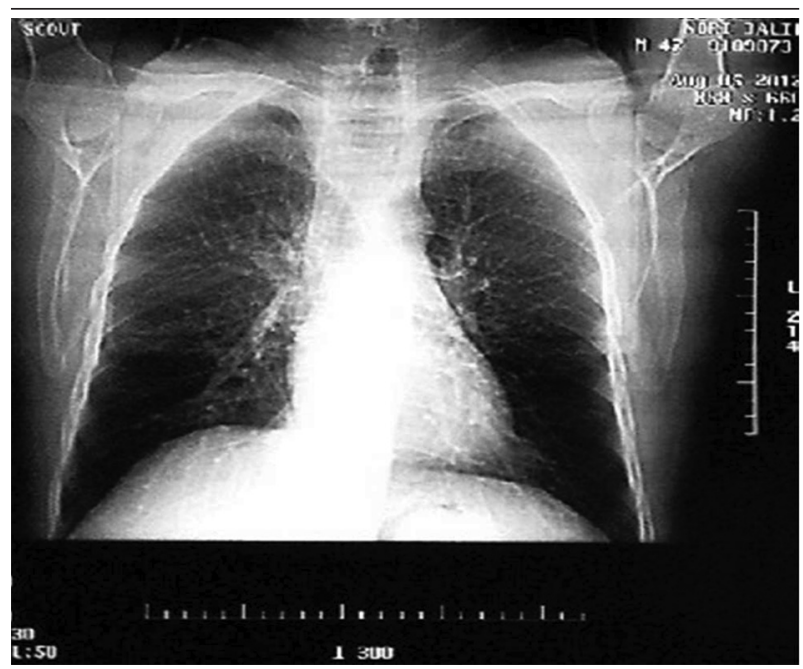

Figure 1. Chest X-Ray Shows Dilatation of the Trachea and Bronchomegaly

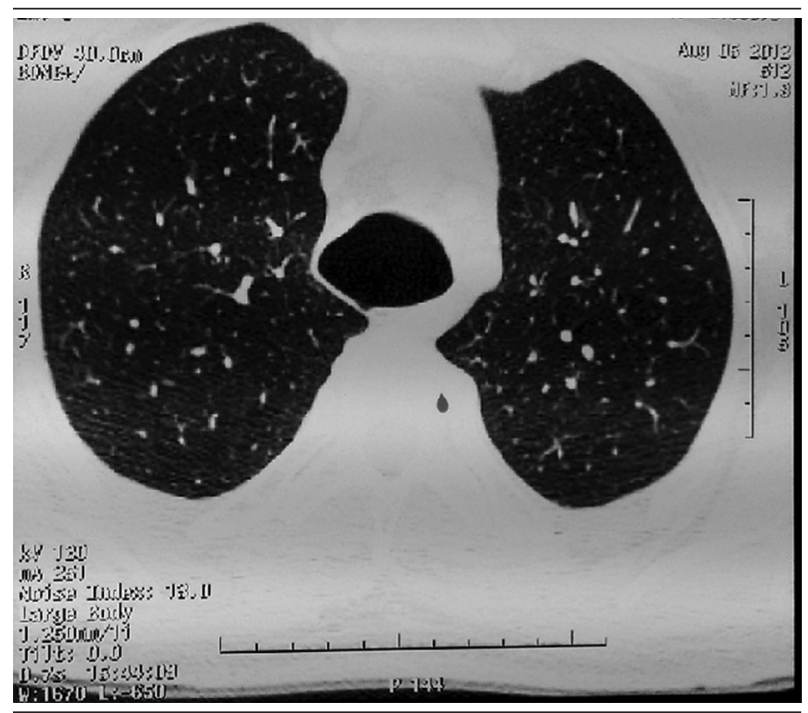

Figure 2. Chest CT Scan in Axial Plane Shows Tracheomegaly

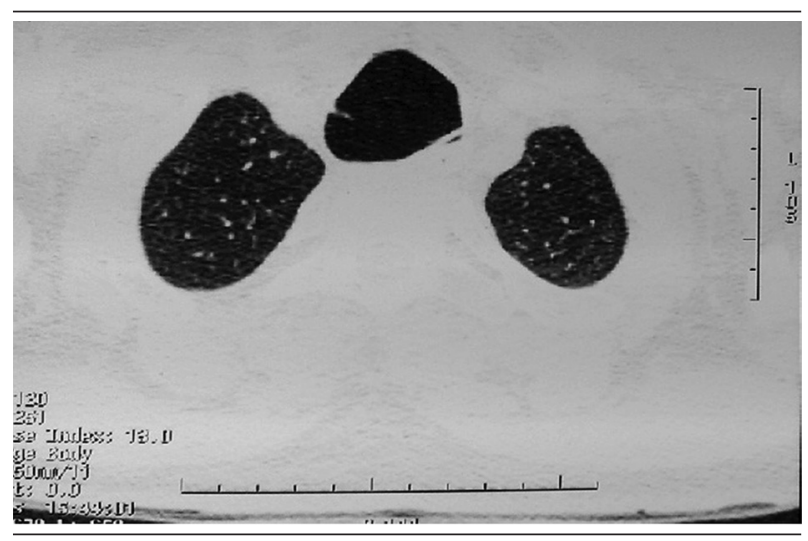

Figure 3. Chest CT Scan Shows Bronchomegaly

\section{Conclusions}

There is currently no effective therapy for this disease. However, treatment is chiefly supportive to relieve dyspnea and other exhausting symptoms. Asymptomatic patients require no specific therapy while symptomatic patients have need of antibiotic therapy and postural drainage. Besides, bronchoscopy and tracheostomy can be used for the management of secretions. Last but not least, it should be pointed out that patients with marked respiratory collapse may undergo endothelial stenting $(10,11)$.

\section{Acknowledgements}

We wish to thank the continuing efforts of bronchoscopy staff of Sasan Hospital.

\section{Authors' Contribution}

Abbas Fadaii took the clinical examination and collected the data. Bahador Bagheri prepared the manuscript.

\section{Financial Disclosure}

The authors declare that there are no conflicts of interest.

\section{Funding/Support}

The authors state that there was no funding or support.

\section{References}

1. Bateson EM, Woo-Ming M. Tracheobronchomegaly. Clin Radiol. 1973;24(3):354-8.

2. Gay S, Dee P. Tracheobronchomegaly-the Mounier-Kuhn syndrome. Br J Radiol. 1984;57(679):640-4.

3. Shin MS, Jackson RM, Ho KJ. Tracheobronchomegaly (Mounier-Kuhn syndrome): CT diagnosis. AJR Am J Roentgenol. 1988;150(4):777-9.

4. Bourne TM, Raphael JH, Tordoff SG. Anaesthesia for a patient with tracheobronchomegaly (Mounier-Kuhn syndrome). Anaesthesia. 1995;50(6):545-6.

5. Johnston RF, Green RA. Tracheobronchiomegaly. Report of Five Cases and Demonstration of Familial Occurrence. Am Rev Respir Dis. 1965;91:35-50.

6. Blake MA, Clarke PD, Fenlon HM. Thoracic case of the day. Mounier-Kuhn syndrome (tracheobronchomegaly). AJR Am J Roentgenol. 1999;173(3):822-5.

7. Sane AC, Effmann EL, Brown SD. Tracheobronchiomegaly. The Mounier-Kuhn syndrome in a patient with the Kenny-Caffey syndrome. Chest. 1992;102(2):618-9.

8. Parris WC, Johnson AC. Tracheomegaly. Anesthesiology. 1982;56(2):141-3.

9. Messahel FM. Tracheal dilatation followed by stenosis in Mounier-Kuhn syndrome. Anaesthesia. 1989;44(3):227-9.

10. Woodring JH, Barrett PA, Rehm SR, Nurenberg P. Acquired tracheomegaly in adults as a complication of diffuse pulmonary fibrosis. AJR Am J Roentgenol.1989;152(4):743-7.

11. Collard P, Freitag L, Reynaert MS, Rodenstein DO, Francis C. Respiratory failure due to tracheobronchomalacia. Thorax. 1996;51(2):224-6. 